\title{
El suicidio por causa ontológica: el caso Mainländer*
}

\author{
Suicide due to ontological causes: Mainländer's case
}

Sandra Baquedano Jer ${ }^{* *}$

\begin{abstract}
Resumen: Cuando la explicación del suicidio se aborda desde la psiquiatría, la psicología o sociología, suele prevalecer una visión crítica que persigue su prevención. En filosofía, es posible poner énfasis en tratar de entender primero, a partir de los casos concretos que atesora la historia del pensamiento, por qué muchas personas pueden llegar a percibir que sus vidas pierden valor por determinadas creencias o puntos de vista hasta el extremo de tornarse filosóficamente inviable. El caso de Mainländer enfrentará al lector a una cosmovisión según la cual el trasfondo de la realidad se vuelve una experiencia tan destructiva, que resulta imposible vivirla sin terminar dañado, optándose simplemente por no perseverar más en ella. Esa ley del sufrimiento es presentada, no obstante, como necesaria para el fin último, el descanso en la paz eterna, la muerte absoluta, la nada. Este artículo sondea cómo el autor de La filosofía de la redención materializa y aduce a razones ontológicas para acabar con su vida, horas después de recibir la impresión fresca de su obra recién publicada.
\end{abstract}

Palabras clave: suicidio, voluntad de morir, muerte absoluta, no ser, nada.

Abstract: When suicide is explained from the point of view of psychiatry, psychology or sociology, a critical perspective often prevails, mainly focusing on its prevention. In philosophy, emphasis is placed firstly on attempting to understand, based on actual cases in the history of thought, why the life's perception of many people can lose value, due to certain beliefs or points of view, to such an extent that life becomes philosophically non-viable. The case of Mainländer confronts the reader with a

\footnotetext{
* Este artículo es resultado parcial de los proyectos Fondecyt 1190021 y 1181322

** Doctora en Filosofía (Universität Leipzig, 2007) y profesora asociada del Departamento de Filosofía de la Universidad de Chile. Entre sus principales libros se encuentran: Filosofía de la redención. Antología de Pbilipp Mainländer (2011) y Wille zur Phantasie. Versuch, das Nichts bei Schopenhauer auszuloten (2007). Es autora de una serie de artículos publicados en revistas indexadas de renombre internacional. Desde el año 2008 hasta la fecha ha sido investigadora de varios proyectos Fondecyt. Dirección electrónica: sandrabaquedano@uchile.cl
} 
cosmovision according to which the background of reality becomes an experience so destructive that it results impossible for one to live without being hurt as a result, thus leaving one with the option to no longer persist with life. This law of suffering, however, is presented as necessary for the ultimate end, that is, resting in eternal peace, absolute death, nothingness. This article explores how the author of The Philosophy of Redemption materialize and adduce ontological arguments on this issue to end with his life barely hours after receiving a fresh copy of his work that had just been published.

Key words: suicide, will to die, absolute death, not being, nothingness

Queda todavía mucho por investigar sobre el suicidio, a pesar de que este problema data de las fuentes de la ética filosófica. Cuando Sócrates aparece en el Critón rechazando una oportunidad que le dan para huir-luego de haber sido acusado y condenado a muerte por el tribunal ateniense- ${ }^{1}$ su decisión no solo conlleva a que termine bebiendo la mortífera cicuta, sino a que se abra una profunda reflexión sobre el acto de darse muerte a sí mismo. Este caso, aunque está en los albores de la metafísica occidental, no es la única puerta de entrada al tema. Tampoco es acceso obligado dar por hecho que el suicidio es la mera interrupción de la vida en algunos individuos sin sondear su posibilidad como el curso natural que pueden seguir algunas de ellas. Este artículo da cuenta de cómo Mainländer aduce al respecto razones ontológicas para acabar con su vida el primero de abril de 1876, horas después de recibir el ejemplar recién publicado de La filosofía de la redención.

\section{Aspectos biográficos de la gestación de una obra que acabó con la vida de su autor}

Philipp Batz es un pensador desconocido para la gran mayoría; no forma parte del canon filosófico. Nació el 5 de octubre de 1841 en la ciudad de Offenbach, situada a orillas del río Main. Su seudónimo en alemán significa precisamente de la región del Main: Mainländer.

En una mirada retrospectiva, él testimonia que tanto su madre como su abuela materna fueron forzadas a casarse por pactos entre terceros, considerándose a sí mismo hijo de una violación conyugal: "Todos nosotros

${ }^{1}$ Cfr. Platón, Diálogos, Critón, Madrid, Gredos, 1992, (44a-d). 
cargamos la mácula de un conflicto feroz. No somos hijos del amor, sino de una violación conyugal". ${ }^{2}$ La turbulenta atmósfera familiar, marcada por este hecho, permite comprender mejor su posterior teorización devota por la virginidad ${ }^{3}$ y la autosupresión de sí. ${ }^{4}$

El joven Philipp luego de recibir parte de la formación secundaria en su ciudad natal, se trasladó a la Escuela de Comercio de Dresde por alrededor de dos años, motivado por su padre, Georg Wilhelm Batz, quien quiso formarlo como comerciante, pese a la fuerte vocación de su hijo por las humanidades.

En 1858 Mainländer emigró a Nápoles para realizar una práctica de comercio. Aprendió el idioma y leyó a los grandes de la literatura italiana en original, pero durante esos años en Italia se sumió en largas depresiones. Padeció un amor no correspondido y el suicidio de su hermano Daniel en Messina, a unas pocas horas de donde vivía. ${ }^{5}$ Tras su deceso, recibió con retraso dos cartas de su hermano fallecido. En la primera le suplicaba que acudiera a Sicilia por él, en la segunda le informaba que había decidido quitarse la vida después de colapsar en la espera. ${ }^{6}$ Ambos sucesos generaron en él una honda afección que exacerbó su deseo de encontrar una liberación al tormento que le significaba la vida. La intención de acelerar el curso de la suya acentuó a la vez su fijación de ser soldado para morir en el campo de batalla, dar la vida por ideales que él consideraba superiores. Ahora bien, la contemplación desinteresada e inspiradora que produjeron en sí sublimes e idílicos parajes naturales ayudaron a compensar su congoja interior. Escribió poemas de amor, dolor, anhelo de morir y experiencias sublimes con la naturaleza, influencias probables de Leopardi. Forjó además en su imaginación lo que llegaría a ser

2 Sommerlad, Fritz, “Aus dem Leben Philipp Mainländers", en Winfried MüllerSeyfarth (ed.) Die modernen pessimisten als décadents": von Nietzsche zu Horstmann. Texte zur Rezeptionsgeschichte von Philipp Mainländers Philosophie der Erlösung, Würzburg, Königshausen und Neumann, 1993, p. 95.

3 Cfr. Mainländer, Philipp, Die Philosophie der Erlösung, Tomo I, Hildesheim/Zürich/New York, Georg Olms, 1996, pp. 215, 219, 263, 334, 338, 575, 600 .

${ }^{4}$ Cfr. Gajardo, Paolo, La supresión de sí como actitud nibilista en Mainländer y Cioran, Tesis de Licenciatura en Filosofía, Santiago de Chile, Universidad de Chile, 2018, pp. 48-58. ${ }^{5}$ Cfr. Rademacher, Guido, Der Zerfall der Welt. Philipp Mainländer, Londres, Turnshare, 2008, p. 47.

${ }^{6}$ Ibid., p. 48. 
después la trilogía de un drama histórico: Die letz̧ten Hohenstaufen, y se aproximó a la filosofía leyendo a Spinoza y a Schopenhauer. Esta última filosofía lo cautivó por completo. ${ }^{7}$

En 1863, Mainländer regresa a su país con la presión de hacerse cargo de la fábrica de cueros del señor Batz, tratando de conducirla lo mejor posible. Vivió un par de años en la casa de sus padres, llevando una vida bastante austera y de especial cuidado a su madre, únicamente abandonaba la casa para trabajar. Discutiendo un día con ella -entre ambos existía un trato muy íntimo y sobreprotector-, en son de broma, le dijo: "Eres una pagana, una hija del mundo, una gran pecadora, y te irás algún día al infierno' ¿Y cuál fue su respuesta? ‘'Si tuviera ahí a mis hijos, estaría contenta!””. ${ }^{8}$ Esa respuesta generó en Mainländer la convicción de que el instinto posesivo del amor materno era nocivo para la humanidad. En 1865, luego de un paseo a orillas del Rin, lo enrostró su agonía y posterior muerte. Fue una pérdida que lo afectó demasiado y que de algún modo buscó canalizar, abocándose de lleno a la vida intelectual e intentando en fallidas ocasiones hacerse soldado para morir por algo que él consideraba valioso.

Vivió cinco años en Offenbach como un ermitaño. Tras la venta de la fábrica en 1868 y de una seguidilla de malos negocios, Mainländer se ve forzado a comenzar a trabajar en un banco en Berlín. ${ }^{9}$ Luego de la extenuante jornada laboral -sobre cuya extensión se pronunció más tarde en su apartado Política, proponiendo en general reducirla como medio de liberación-, ${ }^{10}$ Mainländer se apartaba del mundo para cultivar su erudición. Como autodidacta y en soledad estudió antropología, historia natural, religión, política, ciencias sociales, poesía alemana y, en especial, filosofía. Entretanto el señor Batz había tenido que vender la casa y la familia estaba disuelta. Planeaba llevarse consigo a su hermana Minna a Berlín para mejorar su calidad de vida, pero una vez que fue a buscarla, encontró a su padre enfermo y quiso hacerse cargo de ellos allá. Decidió entonces renunciar al año siguiente a su puesto y gastar su pequeño patrimonio en mantenerlos. Fue en esa época cuando tomó consciencia de la

\footnotetext{
${ }^{7}$ Cfr. Sommerlad, F., “Aus dem Leben Philipp Mainländers”, p. 98.

${ }^{8}$ Ibid., p. 100.

${ }^{9}$ Cfr. Mainländer, P., Die Macht der Motive. Literarische Nachlass von 1857 bis 1875, Tomo

IV, Hildesheim/Zürich/New York, Georg Olms, 1999, p. 325.

${ }^{10}$ Cfr. Mainländer, P., Die Philosophie der Erlösung, Tomo I, p. 296.
} 
necesidad de ordenar sus pensamientos, trazados en diversos escritos y el de aquellos otros que aún estaban solo en su mente.

Redactó en un estado de ensoñación la primera versión de La filosofía de la redención. Centró sus estudios tanto en las obras de Kant como en las de Schopenhauer y en tan solo cuatro meses, bosquejó una segunda versión de la obra, concluyéndola provisoriamente el otoño de 1873. Escribía sin pausa, incluso bajo diversos estados febriles. Estaba tan ensimismado que no se enteró de que la Bolsa de Viena había quedado en bancarrota y que a raíz de eso había perdido casi todo su dinero. ${ }^{11} \mathrm{Al}$ darse cuenta, comenzó a buscar trabajo y tras diversos intentos fue aceptado nuevamente en un banco en Berlín, pero alcanzó a estar solo un período corto en ese puesto que tantas penurias existenciales le provocaba. El suplicio se acabó cuando presentó su renuncia, en marzo de 1874.

Durante el tiempo que le restaba de vida, escribió con máxima intensidad. Como resultado de esas arduas jornadas, dedicado por completo a su obra en Offenbach, concluyó a fines de septiembre el primer tomo de $\mathrm{La}$ filosofía de la redención. Un poco antes, había escrito: "En otoño habrás terminado tu significativo sistema filosófico. Sin duda, sentirás un gran vacío en ti. ¿Cómo quieres llenarlo? (...) ¿No sería necesario que te des paz?”. ${ }^{12}$

Después de un corto tiempo, el filósofo fue llamado a Halberstadt para incorporarse en el regimiento de Magdeburgo como coracero y aceptó. Había escogido el servicio más duro en el cuerpo de caballería. Afirmaba no ser uno de esos individuos que quieren disfrutar de los beneficios públicos sin dar nada de sí ni cumplir con su deber hacia el Estado, luchando por la elevada meta o bien de la humanidad. En marzo de 1875 sostuvo que ya había pasado por todo en cuanto soldado, que sus pensamientos se rozaban, empujaban e incubó el germen de lo que hoy se conoce como el segundo tomo de La filosofía de la redención.

Aunque se había propuesto permanecer tres años en el servicio militar, lo cierto es que solo cumplió uno, abandonó el ejército y regresó a Offenbach a comienzos de noviembre. Al poco tiempo terminó lo que póstumamente se convirtió en el segundo tomo de la obra y sufrió un colapso espiritual. Sentía un enorme vacío, comenzó a repensar la consecuencia entre teoría y praxis.

\footnotetext{
${ }^{11}$ Cfr. Mainländer, P., Die Macht der Motive, Tomo IV, p. 334.

${ }^{12}$ Sommerlad, F., “Aus dem Leben Philipp Mainländers”, p. 104.
} 
Tiempo antes le había abierto el corazón a su hermana Minna y confesado que no podía trabajar para el pueblo y el Estado más que con la pluma.

El 31 de marzo de 1876 recibió en Offenbach la primera edición del primer tomo de La filosofía de la redención. A las horas siguientes, en la noche del 1 de abril, Mainländer se ahorcó.

Tras su muerte, Minna erró por distintos lugares y se hizo cargo tanto de editar como de publicar el segundo tomo de la obra. Cumplida esta tarea se suicidó. Ninguno de los hermanos se casó ni tuvo hijos.

\section{La autosupresión del ser en La filosofía de la redención}

La cosmovisión de Mainländer parte del supuesto que hubo una unidad simple que dejó de existir en cuanto tal, transformando su esencia y fragmentándose por completo en el mundo de la multiplicidad: "Esta unidad simple ha sido (ist gewesen), pero ya no existe (ist) más. Ha transformado su esencia y se ha quebrantado por completo en un mundo de la multiplicidad. Dios ha muerto y su muerte fue la vida del mundo (Gott ist gestorben und sein Tod war das Leben der Welt)". ${ }^{13}$ A diferencia de la muerte de Dios, ya anunciada por Hegel y que años más tarde se popularizó con Nietzsche, esta constatación es distinta. No se trata de una "consciencia desventurada" que representa una de las figuras del Espíritu, ${ }^{14}$ tampoco fueron los seres humanos quienes mataron a Dios, así como vociferaba el hombre loco de la Gaya ciencia, ${ }^{15}$ sino que él mismo fue quien lo hizo. A pesar de que todo lo que es, de algún modo "existía en Dios (in Gott) antes (vor) del mundo", ya no es así: "nosotros no estamos más en Dios" (sind wir nicht mehr in Gott), pues la unidad simple está destruida y ha muerto". ${ }^{16} \mathrm{Al}$ fragmentarse en el mundo, desapareció y sucumbió. Sin embargo, el proceso de autocadaverización en curso está lejos de acabar pues la unidad premundana no se deshizo de inmediato en la nada, sino que surgió el universo de la multiplicidad, con todos sus soles y nebulosas, avizorados

\footnotetext{
13 Mainländer, P., Die Philosophie der Erlösung, Tomo I, p. 108.

${ }^{14}$ Cfr. Hegel, Georg Wilhelm, La fenomenología del espiritu, México, D. F., Fondo de Cultura Económica, 2015, p. 435.

${ }^{15}$ Cfr. Nietzsche, Friedrich, Die fröbliche Wissenschaft, Leipzig, Verlag von E. W. Fritzsch, 1887, pp. 153-155.

16 Mainländer, P., Die Philosophie der Erlösung, Tomo I, p. 108.
} 
desde un mundo en lucha: "todo se encuentra en incesante acción y reacción, obteniendo así el cuadro de un universo en potentísima crispación, tensión. Donde quiera que tenga lugar un movimiento dentro del universo, ninguna cosa quedará intacta frente a él: sufrirá su efecto y reaccionará". ${ }^{17}$ De este modo, por su procedencia, todo se encuentra en una constante correlación dinámica. De ahí que los individuos no sean plenamente autónomos ya que antes fueron una unidad simple (einfache Einheit), y el mundo es obra de ella: "Así pende sobre el mundo de la multiplicidad, a modo de reflejo, la unidad premundana, como si un lazo invisible e irrompible abrazara a todos los seres individuales, siendo este reflejo, este lazo, la correlación dinámica del mundo (dynamische Zusammenhang der Welt)". ${ }^{18}$

El paso del superser, mediante el devenir, hacia el no ser, fue resultado de una autorreflexión. Junto o fuera de la unidad premundana no existía nada ni nadie; Dios se encontraba en una suerte de absoluta soledad. La transición del campo trascendente hacia el inmanente supone precisamente que no fuera motivado ni impedido por algo externo a ejecutar la gran obra:

Dios existió solo, en absoluta soledad y, en consecuencia, es correcto sostener que por nada externo fue limitado; su poder era, en este sentido, omnipotente, dado que nada situado fuera (außer) de él lo limitó. Sin embargo, no era una omnipotencia frente a su propio (eigenen) poder, o, en otras palabras: su poder no podía destruirse por sí mismo, la unidad simple no pudo dejar de existir por sí misma. Dios tuvo la libertad de ser (sein) como quiso; pero no era libre de su determinada esencia (Wesen). Dios tuvo la omnipotencia de ejecutar su voluntad y de ser (sein) de cualquier forma, pero no tuvo el poder de no (nicht) ser al mismo tiempo. ${ }^{19}$

La omnipotencia suya estaba en relación con la esfera del ser, que lo era todo; fuera de sí, no existía nada. Mas, precisamente, ese nibil fue su único límite, el obstáculo que le impidió al autoaniquilarse ingresar de inmediato en el no ser.

Al ser concebida la unidad simple en la trascendencia como el ser más perfecto, tras su resolución divina no pudo Dios haber aspirado en su suma

\footnotetext{
${ }^{17}$ Ibid., p. 86.

18 Ibid., p. 105.

${ }^{19}$ Ibid., p. 324.
} 
perfección a ser mejor y distinto a lo que fue. ${ }^{20}$ Solo tenía la posibilidad de ser o no ser, y La filosofía de la redención signa la prevalencia de su negativa, cuyo logro inmediato, si bien no se cumplió instantáneamente, fue el trance que permitió el origen de la vida, abrazando todo en el universo consciente o inconscientemente el acto de no ser.

Mainländer sostiene que en sentido estricto, la libertad solo atañe al campo de la trascendencia, al de la unidad simple y su tranquilidad, es decir, a Dios antes del universo, ${ }^{21}$ pero cometido el suicidio, cuando muere y nace el mundo, se genera la vida, en el curso vital del campo inmanente de la multiplicidad; el movimiento desencadenado con estricta necesidad, que no es distinto al lento proceso de desintegración divina: "La desintegración originaria de la unidad en la multiplicidad marcó la tendencia de todos los movimientos posteriores, de este modo, proliferaron continuamente las contradicciones en todos los campos". ${ }^{22}$ Su descomposición que tiende hacia la multiplicidad inmanente llamada humanidad no es infinita pues el universo no surgió por un acto de creación, sino más bien por uno de agotamiento de voluntad divina:

Esa obra de Dios -la desintegración en la multiplicidad- se representa entonces como la realización (Ausfübrung) del acto lógico de la decisión (Entschlusses) de no ser, o, en otras palabras: el mundo es el medio (Mittel) para lograr el objetivo (Zwecke) de no ser, y el mundo, en verdad, es el único (eiñig) medio posible (mögliche) para alcanzar dicho fin. ${ }^{23}$

Para su consumación final en el nibil negativum, la suma total de fuerzas presentes en cada fragmento ha de estar madura para la muerte. En este contexto, la autoconsciencia puede posibilitar negar perpetuarse y tender hacia la autoaniquilación a fin de consumar el gran ciclo de redención del ser mediante la supresión de sí. El tránsito del ser a la nada culmina en el no ser y la vida de cada cual es solo parte de la secuela de un Dios que resolvió suicidarse.

${ }^{20}$ Cfr. Mainländer, P., Die Philosophie der Erlösung, Tomo II, p. 509.

21 Cfr. Ibid., p. 507.

22 Ibid., p. 300.

${ }^{23}$ Mainländer, P., Die Philosophie der Erlösung, Tomo I, p. 325. 


\section{La prefiguración mainländeriana del Big Bang en el suicidio de Dios en cuanto origen de la vida en el universo}

$\mathrm{Al}$ exponer Mainländer una visión suya acerca del origen del universo a partir de lo que pudo haber sido la explosión originaria de una unidad simple, trascendente -denominada por él mismo Dios, y que resolvió que la no existencia es mejor que la existencia, autodestruyéndose conforme a su negativa-, prefiguró con un lenguaje poético y a través de sus propias premisas vivenciales una particular cosmovisión de lo que casi un siglo más tarde la ciencia llegó a llamar Big Bang. ${ }^{24}$

La unidad premundana, rebasada de su propio superser, omnipotente ante el ser, pero no así ante el no ser, al suicidarse, se fragmentó en el mundo de la multiplicidad y continúa extendiéndose en su descarga energética hasta el exterminio de toda su precedencia, cuyo curso irreversible de fricción se encuentra aún presente existiendo, pero deviniendo hacia su extenuación.

Desde el punto de vista de la físico-química moderna muchas de estas

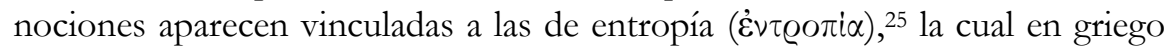
significa cambio, transformación o evolución. Este concepto junto al de muerte térmica fue desarrollado desde un punto de vista científico por Rudolf Clausius durante la segunda mitad del siglo XIX. ${ }^{26}$ Ludwig Boltzmann, un año después del suicidio de Mainländer, le dio una expresión matemática a la entropía desde el punto de vista de la probabilidad, en el contexto de la mecánica estadística; y tras décadas de este aporte acabó también con su vida. La entropía puede ser considerada una variante de la ley de la conservación de la energía. En

${ }^{24}$ Cfr. Kaufmann, William, Galaxies and Quasars, San Francisco, W. H. Freeman and Company, 1979; Silk, Joseph, A Short History of the Universe, New York, Scientific American Library, 1994; Taylor, John, When the Clock Struck Zero, New York, St. Martin's Press, 1993; Trinh, Xuan Thuan, The Birth of the Universe: The Big Bang and After, New York, Harry N. Abrams, Inc., 1993.

${ }^{25}$ Cfr. Penrose, Roger, The Road to Reality: A complete Guide to the Laws of the Universe, New York, Alfred A. Knopf, 2005; Schrödinger, Erwin, What is life? The Physical Aspect of the Living Cell, Cambridge, Cambridge University Press, 1944.

${ }^{26}$ Clausius, Rudolf, "Über die bewegende Kraft der Wärme", Annalen der Physike und Chemie, 79, 1850 pp. 368-397 y 500-524; "Über verschiedene für die Anwendung bequeme Formen der Hauptgleichungen der mechanischen Wärmetheorie", Annalen der Physik und Chemie, 125, 1865, pp. 351-400. 
determinadas instancias la energía se conserva, pero existen partes que pasan a un estado en el que no pueden volver a transformarse. La entropía alude en un lenguaje no técnico al grado de desorden de un sistema. El rol fundamental que juega en la dinámica de sistemas complejos queda en este caso explícitamente mencionado en la segunda ley de la termodinámica y la del caos e irreversibilidad de procesos elementales, según lo formula, por ejemplo, el científico ruso -premio Nobel en Química-, Ilya Prigogine. ${ }^{27}$

En el proceso irreversible de desintegración de la unidad simple trascendente en la multiplicidad inmanente, todos los fragmentos, en cuanto voluntades individuales dotadas de vida, van debilitando las fuerzas que requieren para su propia conservación. Tras la constante fricción y lucha pierden así las energías que los conforman. Sin embargo, unos antes y otros después, encontrarán igualmente su fin último en la muerte. Mainländer sostiene que la ley del debilitamiento de las fuerzas que rige en el universo llegará a completo término en el nibil negativum, imponiéndose tácitamente en el universo la entropía en una suerte de tendencia termodinámica de muerte.

Denominar Dios a esa unidad originaria, trascendente -que resolvió que la no existencia es mejor que la existencia, autodestruyéndose conforme a su negativa-, implica hacer extensible su suicidio a modelos astrofísicos. Ahora bien, este Big Bang parece ser más la abstracción allegorica de un fenómeno sensu stricto que una explicación científica de la evolución cósmica, pero aplicar el suicidio a modelos astronómicos puede ayudar a sondear ciertas tendencias autodestructivas arraigadas en lo más íntimo de cada cual.

De esta manera, al considerar las leyes físicas subyacentes tras los procesos que van desde el origen del universo y su evolución hasta nuestros días, la teoría mainländeriana del "comienzo-final" de todos los tiempos retrotrae a una vuelta repentina e inconcebible de perfección, sin tiempo ni espacio, que tiende hacia la nada, dejando en su curso al descubierto una serie de aportes que pueden adjudicársele además al aumento de la entropía, a la

27 Cfr. Prigogine, Ilya; Dewel, Guy y Kondepudi, Dilip, "Chemistry far from the equilibrium: Thermodynamics, Order and Chaos", en Nina Hall (ed.), The New Chemistry, Cambridge, Cambridge University Press, 2000; Prigogine, Ilya, The End of Certainty: Time, Chaos and the New Laws of Nature, New York, The Free Press, 1997; Prigogine, Ilya y Nicolis, Gregoire, Self-Organization in Nonequilibrium Systems: From Dissipative Structures to Order through Fluctuations, New York, J. Wiley \& Sons, 1977. 
teoría del caos y a los postulados que dicen relación con las leyes de la termodinámica.

\section{Antecedentes del acto de darse muerte a sí mismo en la voluntad de vivir y las discrepancias fundamentales respecto a la voluntad de morir}

La gente se aferra a la vida, quiere a toda costa vivir. El instinto de sobrevivencia suele ser más fuerte y sobreponerse a las miserias del mundo, pasando incluso por alto la convicción personal a la que se pueda llegar en algún momento de que esa vida de uno no vale la pena seguir viviéndola. De ahí que tanto Schopenhauer como Mainländer enfaticen el rol esencial de la voluntad. Este pensador se valió de aspectos fundamentales de la metafísica de la voluntad de vivir de Schopenhauer, pero se distanció, modificó y trastocó también sustancialmente ciertas nociones de la misma, llegando a resultados radicalmente distintos, como sucede en el caso del suicidio.

Voluntad de vivir: En la metafísica schopenhaueriana, el noúmeno volente es el núcleo más íntimo del ser humano. Esta única voluntad cósmica está más allá del tiempo, del espacio y la causalidad, y se objetiva en la multiplicidad de los fenómenos, de forma tal que tiende innata y universalmente a afirmar el $\operatorname{ser}^{28}$. Al mostrarse el propio cuerpo como un conjunto de impulsos cuya esencia es voluntad, por extensión deduce que lo mismo ocurre en el resto del universo, es decir, en las fuerzas de atracción, repulsión, renovación, etc. Todo es fenómeno, salvo la voluntad, cuya objetivación constituye el mundo como representación. Al ser cosa en sí, no se halla sometida al principio de razón ni a necesidad alguna. Por naturaleza es una afirmación absolutamente libre e insaciable de sí, una ansiedad metafísica ciega que no tiene otro fin que mantenerse en el ser. En los seres vivos se reduce en una primera instancia a la conservación del individuo y luego a la perpetuación de la especie, pese a que no todos son aptos y útiles para servir de este modo a la voluntad.

Voluntad de morir: Para Mainländer el ser es lisa y llanamente la tendencia innata, la energía que va sin representación a consumar su meta en el no ser. A diferencia de la voluntad de vivir schopenhaueriana, La filosofía de la redención comprende todo lo que yace tras los fenómenos como voluntades individuales

${ }^{28}$ Cfr. Schopenhauer, Arthur, Die Welt als Wille und Vorstellung I. Sämtliche Werke. Tomo I, Stuttgart/Frankfurt, Suhrkamp Taschenbuch Verlag, 1986, pp. 171-173. 
de morir. Entre ellas forman parte de un inconsciente, alojado en el yo de cada cual, que no es de carácter universal. Tampoco existe un monismo de la voluntad como en Schopenhauer, sino un individualismo de la misma. Las voluntades individuales de vivir, destinadas a luchar por su existencia, a fin de asegurársela, entran en disputa, fricción y roce, como si en el fondo existiera una causa final. Sin embargo, lo que en verdad quieren no es vivir, puesto que la vida es solo apariencia de la voluntad de morir, la cual albergan en lo más íntimo de su esencia: "La vida (Leben) no se quiere (gewollt), sino que es solo fenómeno (Erscheinung) de la voluntad de morir (Willens zum Tode)". ${ }^{29}$ Cada una de ellas corresponde a una transformación que ha sufrido la unidad trascendente en una multiplicidad inmanente, una alteración de su esencia, siguiendo desde su interior el impulso trazado por la unidad simple. A pesar de que la voluntad humana sigue necesariamente esa tendencia connatural que le concierne, desde ella es posible sondear su destino y proyectar alguna forma de liberación. La máxima expresión de esta consciencia es cuando se reconoce que lo esencial no es aquella voluntad que persigue la vida, sino aquella que sirve como medio y tiene como fin último la muerte.

El suicidio como un acto de afirmación de la voluntad de vivir, opuesto al camino ético de la renuncia y negación: Schopenhauer sostiene que la voluntad en cuanto cosa en sí es la biografía de una realidad que termina siendo perjudicial por naturaleza, pero si es motivada por un conocimiento emancipado de la misma puede llegar en el ser humano a la negación de ese summum malum. En este sentido, su ética es contranatura ya que precisamente proviene de acciones derivadas de la negación de dicho impulso primordial. La moral se deriva de acciones provenientes de un conocimiento originario e intuitivo que se vuelve consciente tanto del dolor como de la vacuidad del querer. El problema del suicidio se resume en que quien lo comete no sigue esta vía de renuncia, pues no deja de querer; afirma en la adversidad las ganas de haber llevado una vida más afortunada, sin tormentos, por motivos que nacen de un yo volente, marcado visiblemente por las barreras propias del principium individuationis. ${ }^{30}$ Cuando las circunstancias no permiten gozar de esa vida o superar un determinado padecimiento, quien se da muerte a sí mismo obraría, conforme a su naturaleza como voluntad metafísica. Algo muy diferente a quien sigue la

\footnotetext{
${ }^{29}$ Mainländer, P. Die Philosophie der Erlösung, Tomo I, p. 330; Tomo II, p. 212.

${ }^{30}$ Cfr. Schopenhauer, A., Die Welt als Wille und Vorstellung I, p. 541.
} 
vía ascética o la del renunciante que siente aversión hacia los goces de la vida, negando su esencia, es decir, el querer vivir. Schopenhauer nunca plantea como salida al problema de la existencia humana el cese abrupto, violento y autodestructivo de la vida, sino, por el contrario, un camino lento de luchas internas, en el cual se busca negar el querer que provoca dolor en los demás y en uno. Sostiene que Cristo y la doctrina de Buda son personificaciones alegóricas de lo que su filosofía plantea en sentido estricto como negación de la voluntad de vivir. ${ }^{31}$

El suicidio como un acto de aniquilación de sí, posible de seguir en la senda ética y natural hacia el no ser. Mainländer efectúa una transmutación del concepto de negación (Verneinung) schopenhaueriano por el de aniquilación (Vernichtung). Desde esta cosmovisión, el sentido de la vida, del ser en cuanto cosa en sí, es el mismo que sigue el universo en su afán expansivo hacia el no ser. $\mathrm{Al}$ concebir el destino universal de la historia como la agonía que persiste en los fragmentos que correspondieron a un Dios, defiende, por lo tanto, en algunos casos, el suicidio como un medio para acelerar dicho proceso natural de autocadaverización en curso, aliviando de este modo aquel dolor irreversible. Sobre este aspecto, si bien señala que La filosofía de la redención no exhorta en general al suicidio, por mor de la verdad despeja y destruye contramotivos de enorme poder que condenan el acto y a quienes lo cometieron: "En cuanto ser humano (als Mensch), Schopenhauer se sitúa frente al mismo completamente libre de prejuicios, algo que valoro enormemente en él. Solo seres humanos fríos, inclementes o reprimidos por dogmas pueden condenar a un suicida. ¡Qué ventura que una mano indulgente haya abierto una puerta, por la cual cuando se nos haga insoportable el sofocante calor de la sala de la vidapodamos ingresar a la quieta noche de la muerte! Solo el despotismo más craso puede castigar el intento de suicidio". 32 Ahora bien, en La filosofía de la redención aparece la moral cristiana como un mandamiento de suicidio lento. ${ }^{33}$ Desde esta perspectiva, no solo Cristo, sino también Buda, habrían expresado el suicidio sensu allegorico a través de sus vidas, realizando y enseñando en el fondo el camino hacia el no ser: en el reino de los cielos y en el nirvana, respectivamente.

${ }^{31}$ Cfr. Die Welt als Wille und Vorstellung I, p. 550, y II, pp. 806-807.

32 Mainländer, P., Die Philosophie der Erlösung, Tomo I, p. 546.

${ }^{33}$ Cfr. Mainländer, P., Die Philosophie der Erlösung, Tomo II, p. 218. 
La inutilidad del acto suicida, la nada ilusoria: Schopenhauer no valida la efectividad del acto de darse muerte a sí mismo. El hecho de que la voluntad, por sobre el fenómeno del nacimiento y la muerte, jamás deje de manifestarse, es argumentación suficiente para calificar el suicidio de un acto inutil. La destrucción voluntaria del cuerpo, es decir, de la objetivación más directa de la cosa en sí, en este tiempo y lugar, deja la voluntad de vivir intacta. Al no ser negada, la nada es ilusoria. La crítica schopenhaueriana apunta a que el suicidio es un modo equívoco de enfrentar el sufrimiento, pues se anula en el acto el único camino válido donde puede proyectarse un ideal de redención. ${ }^{34}$ Así, se realza el hecho de que la voluntad no puede ser destruida más que por el conocimiento o la consciencia. Puesto que ningún acto de violencia puede aspirar jamás a dicho fin, desestima las consecuencias de orden ontológico del suicidio, deslegitimando su eficacia. Al rechazar los efectos prácticos e inmediatos del suicidio -incluso en casos psiquiátricos en los cuales se da una ausencia de condiciones que permitan acceder a un conocimiento mejor o a una consciencia continua que posibiliten negar la voluntad de vivir-, Schopenhauer parece alejarse mediante su concatenación argumentativa no de la temática concerniente al dolor, sino de su vivencia, que, teorizada hasta la neta abstracción, no dimensiona que quien padece un dolor tan intenso puede olvidar todo credo o proyección de vida individual y eterna. De perpetuarse esa vida, sería prolongar una tortura. Muchas parecen ser las causas que pueden desencadenar un suicidio, pero cuales sean las razones suficientes que se den para intentar explicar una resolución de esa índole no suelen ser fuente definitiva de comprensión para quien ha sentido compasión por alguien que lo cometió. Aun cuando muchos de ellos se figuraron, antes de suicidarse, que dicho acto podría acarrear comenzar de nuevo con otra vida, en peores condiciones aún, indiferentes hubieron de imaginársela, porque fue la propia la que no se sintieron capaces de seguir soportando. Por eso el suicidio es realizado sin distinción de creencias por personas que padecieron de profundis algún tormento físico o espiritual, independientemente de si había en el fondo una explicación psicopatológica o no.

34 Cfr. Schopenhauer, A., Die Welt als Wille und Vorstellung I, pp. 542-543; Schopenhauer, A., Parerga und Paralipomena II, Sämtliche Werke. Tomo V, Stuttgart/Frankfurt, Suhrkamp Taschenbuch Verlag, 1986, p. 367. 
La efectividad del suicidio, la nada efectiva tras el acto: Mainländer lanza fuertes invectivas contra la calificación del suicidio como un acto infructuoso:

Schopenhauer, sin fundamento concluyente alguno, menoscaba el suicidio en general como un acto inútil (...). Esto es falso (...). Asume el gesto de haberse enterado, con toda exactitud y por la fuente más segura, de lo que sucede con un suicida después de la muerte. La verdad es que el suicida, en cuanto cosa en sí, es aniquilado en la muerte, tal como todo otro organismo. Si no pervive en otro cuerpo, la muerte es su aniquilación absoluta (absolute); en otro caso, solo se escapa de la vida con su parte más débil. Detiene la rueda que, si no, habría rodado por un rato, después de haber sido abandonada por la fuerza que la mueve". 35

Mainländer, sostiene que quien se suicida, si no ha dejado descendencia biológica, su muerte no será relativa, sino absoluta, alcanzando tras el acto una nada efectiva.

\section{El consuelo en la muerte absoluta: el descanso en la paz eterna, la nada}

El debilitamiento de la fuerza que rige las leyes universales está marcado por el sufrimiento. ${ }^{36}$ Cada cual lucha por conservar su existencia y luego perpetuarla, pero al hacerlo, directa o indirectamente, provoca y padece dolor, debilitando con ello tanto las fuerzas suyas como las del resto. Las voluntades egoístas, dispuestas unas contra otras en su constante fricción se obstaculizan y dañan mutuamente.

Al ser considerada la vida en su núcleo más íntimo, sufrimiento, optar por no reproducirse implica, dejar en manos de cada uno la posibilidad de poner fin a los futuros tormentos, dado que al fallecer se alcanza un tipo de muerte que es calificada de absoluta, a diferencia de quien pervive en sus hijos y en sucesivos organismos, cuya muerte es de índole relativa, en cuanto, habrá emprendido una nueva vida cuya extensión no se podrá determinar ni tampoco aliviar. Haber emergido por la ignorancia o la indolencia de los progenitores relativa al nacimiento -concebido como el origen y principio de todas las tragedias-, no libera de la propia vida a padres ni a hijos biológicos. Sin

\footnotetext{
35 Mainländer, P., Die Philosophie der Erlösung, Tomo I, p. 546.

${ }^{36}$ Cfr. Mainländer, P., Die Philosophie der Erlösung, Tomo II, p. 510.
} 
embargo, sondear el cese pacífico y voluntario de ese tipo de descendencia posibilita renunciar a traer irreflexivamente a un nuevo ser, una decisión en la que se juega seguir viviendo a través de otros seres o ser aniquilado con la muerte.

Si bien el ser humano tiene la tendencia innata a personificar de forma mística esa nada absoluta como un lugar de paz eterna, nirvana o city of peace, Mainländer plantea que más allá del mundo, no hay ni un paraíso ni un infierno, sino solo la nada. A su ingreso no encontrará reposo ni movimiento, estará en un estado inexistente como en el sueño, pero señala que con la gran diferencia de que aquello que en un estado de ensueño estaba ausente ya no existe más, manifestando su plena convicción que la voluntad se aniquila por completo:

el sabio solo escoge el horror de la aniquilación, ponderando la nada absoluta, y renuncia a la voluptuosidad; pues luego de la noche viene el día, después de la tormenta la dulce paz del corazón, tras cielo tormentoso la pura bóveda etérea, cuyo brillo es turbado cada vez menos y menos por una pequeña nubecilla (la intranquilidad debida al impulso sexual), y luego la muerte absoluta: jla redención de la vida!, la liberación de sí mismo! (Erlösung vom Leben, Befreiung von sich selbst!)". ${ }^{37}$

Mainländer fue un autodidacta que sufrió pérdidas importantes, que sorteó trabajos que le resultaron enajenantes, pero que los logró sobrellevar algunos años, estudiando en soledad filosofía mientras bosquejaba entre frases crípticas y a veces digresivas lo que sería La filosofía de la redención. Tras terminar de escribirla y haber confesado que no podía trabajar más que con la pluma, se da muerte a sí mismo en un acto de congruencia con las premisas ontológicas forjadas por él en su obra capital. El supremo cumplimiento, que se atrevió a acometer, fue la abdicación en pro y por mor de la nada, cuyo llegar a ser lo anuló al acabar con su vida. En este caso, anulándose a sí mismo como resultado de una avidez vital de la nada efectiva que se trascendió a sí misma. Con el desenlace fatal de su vida, horas después de recibir el ejemplar recién publicado de La filosofía de la redención, se inicia el legado de una obra impactante en todo sentido, que requiere una exégesis crítica de profundis y que difícilmente pueda dejar indiferente a alguien que la lea en profundidad.

${ }^{37}$ Mainländer, P., Die Philosophie der Erlösung, Tomo I, pp. 340-341. 


\section{Referencias bibliográficas}

- Clausius, Rudolf, “Über die bewegende Kraft der Wärme”. Annalen der Physik und Chemie 79, 1850, pp. 368-397, 500-524.

- Clausius, Rudolf, "Über verschiedene für die Anwendung bequeme Formen der Hauptgleichungen der mechanischen Wärmetheorie". Annalen der Physike und Chemie 125: 351-400, 1865.

- Gajardo, Paolo, La supresión de sí como actitud nibilista en Mainländer y Cioran, Tesis de Licenciatura en Filosofía, Santiago de Chile, Universidad de Chile, 2018.

- Hegel, Georg Wilhelm, La fenomenología del espiritu, Trad. Wenceslao Roces, México, D. F., Fondo de Cultura Económica, 2015.

- Kaufmann, William, Galaxies and Quasars, San Francisco, W. H. Freeman and Company, 1979.

- Mainländer, Philipp, Die Philosophie der Erlösung, 2 vols., Hildesheim/Zürich/New York, Georg Olms, 1996.

- Mainländer, Philipp, Die Macht der Motive. Literarische Nachlass von 1857 bis 1875, Tomo IV, Hildesheim/Zürich/New York, Georg Olms, 1999.

- Nietzsche, Friedrich, Die fröhliche Wissenschaft, Leipzig, Verlag von E. W. Fritzsch, 1887.

- Penrose, Roger, The Road to Reality: A complete Guide to the Laws of the Universe, New York, Alfred A. Knopf, 2005.

- Platón, Diálogos, Critón, Vol. VI. Trad. María Ángeles Durán y Francisco Lisi. Madrid, Gredos, 1992.

- Prigogine, Ilya; Dewel, Guy y Kondepudi, Dilip, "Chemistry far from the equilibrium: Thermodynamics, Order and Chaos", en Nina Hall (ed.), The New Chemistry, Cambridge, Cambridge University Press, 2000.

- Prigogine, Ilya y Nicolis, Gregoire, Self-Organization in Nonequilibrium Systems: From Dissipative Structures to Order through Fluctuations, New York, J. Wiley \& Sons, 1977. 
- Prigogine, Ilya, The End of Certainty: Time, Chaos and the New Laws of Nature, New York, The Free Press, 1997.

- Rademacher, Guido, Der Zerfall der Welt. Philipp Mainländer, Londres, Turnshare, 2008.

- Schopenhauer, Arthur, Die Welt als Wille und Vorstellung I. Sämtliche Werke. Tomo I, Stuttgart/Frankfurt, Suhrkamp Taschenbuch Verlag, 1986.

- Schopenhauer, Arthur, Die Welt als Wille und Vorstellung II. Sämtliche Werke. Tomo I, Stuttgart/Frankfurt, Suhrkamp Taschenbuch Verlag, 1986.

- Schopenhauer, Arthur, Parerga und Paralipomena II, Sämtliche Werke. Tomo V, Stuttgart/Frankfurt, Suhrkamp Taschenbuch Verlag, 1986.

- Schrödinger, Erwin, What is life? The Physical Aspect of the Living Cell, Cambridge, Cambridge University Press, 1944.

- Silk, Joseph, A Short History of the Universe, New York, Scientific American Library, 1994.

- Sommerlad, Fritz, "Aus dem Leben Philipp Mainländers", en Winfried Müller- Seyfarth (ed.) Die modernen pessimisten als décadents": von Nietzsche zu Horstmann. Texte zur Rezeptionsgeschichte von Philipp Mainländers Philosophie der Erlösung, Würzburg, Königshausen und Neumann, 1993.

- Taylor, John, When the Clock Struck Zero, New York, St. Martin's Press, 1993.

- Trinh, Xuan Thuan, The Birth of the Universe: The Big Bang and After, New York, Harry N. Abrams, Inc., 1993.

Recibido: 03/2020. Aceptado: 06/2020 